\title{
Heterogeneity and redistribution in financial crises
}

\author{
Keiichiro Kobayashi \\ Keio University/The Canon Institute for Global Studies \\ Daichi Shirai \\ The Canon Institute for Global Studies
}

August 15, 2014 (First version: October 18, 2013)

※Opinions expressed or implied in the CIGS Working Paper Series are solely those of the author, and do not necessarily represent the views of the CIGS or its sponsor.

※ CIGS Working Paper Series is circulated in order to stimulate lively discussion and comments.

※Copyright belongs to the author(s) of each paper unless stated otherwise. 


\title{
Heterogeneity and redistribution in financial crises*
}

\author{
Keiichiro Kobayashi ${ }^{\dagger}$ and Daichi Shirai ${ }^{\ddagger}$
}

August 15, 2014 (First version: October 18, 2013)

\begin{abstract}
This paper presents a simple heterogeneous agent economy model in order to show that the redistribution of wealth among heterogeneous agents can play a significant role in the propagation mechanism of financial crises. In an economy where firms with heterogeneous productivity operate under borrowing constraints, the redistribution of wealth reproduces hump-shaped responses for output and labor and procyclicality in observed productivity. In this model, a financial shock generates a persistent and hump-shaped response, whereas a productivity shock does not. It is also shown that the redistribution of wealth significantly amplifies the persistence and hump shape of output and labor in response to a financial shock. This model suggests that redistribution may thus be one of the key driving forces behind the transmission of financial crises.
\end{abstract}

Keywords: Heterogeneity, borrowing constraints, redistribution of wealth, labor wedge

JEL Classification Codes: E10, E32, G01

*Previous versions of this paper were circulated under the title "Heterogeneity and redistribution shocks in business cycles." We thank the two anonymous referees, R. Anton Braun, Selahattin Imrohoroglu, Masaru Inaba, Nobuhiro Kiyotaki, Kengo Nutahara, and seminar participants at the 2013 JEA autumn meeting, BOC-BOJ Joint Conference, Keio University, the 2014 GRIPS macro conference, and the 2014 Asian Meeting of the Econometric Society for helpful comments and discussions. All remaining errors are ours.

${ }^{\dagger}$ Keio University/ CIGS / RIETI. Email: kobayasi@econ.keio.ac.jp

${ }^{\ddagger}$ The Canon Institute for Global Studies. Email: shirai.daichi@canon-igs.org 


\section{Introduction}

This paper aims to shed some light on the propagation mechanism of financial crises by showing that the redistribution of wealth among heterogeneous agents could be a key factor to understanding the features of protracted recessions. The model presented herein implies that the redistribution of wealth can amplify a financial shock in such a way that output and labor display conspicuous persistence and hump shapes and that productivity varies procyclically.

Empirical studies of business cycles show that the responses of macroeconomic variables to exogenous shocks are persistent and hump-shaped (see Christiano, Eichenbaum and Evans (1999) on monetary policy shocks and Altig, Christiano, Eichenbaum and Linde (2011) on technology shocks). Indeed, the reproduction of this persistence and humpshaped response is one of the goals that motivate business cycle theorists (e.g., Carlstrom and Fuerst, 1997; Bernanke, Gertler and Gilchrist, 1999). In this vein, Reinhart and Rogoff (2009) report the conspicuous persistence of macroeconomic variables after a financial crisis, showing that output continues to decrease for two years, on average, whereas it decreases for only one year or less as a result of business cycle fluctuations. Kehoe and Prescott (2007) define "great depressions," namely the large recessions in the aftermath of financial crises, as the time period during which detrended output per capita decreases for more than 10 years, with the accumulated decrease more than $15 \%$, as measured from the beginning of the decade, and $20 \%$ during the whole period. According to the KehoePrescott definition, such great depressions broke out globally throughout the twentieth century, such as in the 1970s in New Zealand and Switzerland and in the 1990s in Japan. By analyzing these episodes, Kehoe and Prescott (2007) conclude that the primary driving force of great depressions is a decline in (observed) productivity. Business cycle accounting (BCA; Chari, Kehoe and McGrattan, 2007) compares productivity with other factors that induce business fluctuations. In particular, BCA focuses on four wedges: the efficiency wedge (EW), labor wedge (LW), investment wedge (IW), and government wedge (GW). EW is observed total factor productivity; LW is MRS/MPL, where MRS is the marginal rate of substitution between consumption and leisure and MPL is the marginal product 
of labor; IW is the wedge between the market interest rate and the stochastic discount factor; and GW is the deadweight loss, which manifests itself as government consumption in a simple real business cycle model. Chari et al. (2007) note that EW and LW are the two primary factors that explain the Great Depression of the 1930s in the United States, while Kobayashi and Inaba (2006) stress the same factors for the lost decade of Japan in the 1990s. Indeed, a growing body of research on BCA has focused considerable attention on how a deterioration in LW affects large recessions (see Mulligan, 2002; Shimer, 2009). A sharp decline in LW was also observed in the US economy during the Great Recession of 2008-2010 (Pescatori and Tasci, 2011).

These studies imply that a theoretical framework for the analysis of persistent recessions in the aftermath of financial crises should have the following three features:

i. Persistent and hump-shaped response of macroeconomic variables to exogenous shocks,

ii. EW should display procyclicality, and

iii. LW should display procyclicality.

Based on the foregoing, in this study we present a simple model that successfully reproduces these three features, even though the reproduction of the third point is slightly problematic. The model used in the present study is a heterogeneous agent economy one with borrowing constraints, wherein a financial shock reproduces responses in line with the first and second features through the redistribution of wealth among heterogeneous agents. In addition, the responses to an aggregate productivity shock display lesser persistence and no hump shape. In our model, LW is procyclical only in response to an extremely large financial shock.

There are two main strands of research on business cycles. The first research stream focuses on standard dynamic stochastic general equilibrium (DSGE) models (Christiano, Eichenbaum and Evans 2005; and Smets and Wouters 2003), wherein the individual behavior of a representative agent is persistent and hump-shaped due to nominal rigidities, the habit persistence of consumption, and the specialized adjustment costs of investments. The second centers on "heterogeneous agent models" such as the credit cycle model pre- 
sented by Kiyotaki and Moore (1997) and the liquidity shock model of Kiyotaki and Moore (2012). Although the individual behavior of each agent in this setting does not display nonlinearity or relatively less persistence, the macroeconomic variables are hump-shaped and strongly persistent as a result of aggregation.

The model used in this study is a heterogeneous agent model. As Cordoba and Ripoll (2004) point out, the hump shape in the model put forward by Kiyotaki and Moore (1997) depends on specific functional forms of utility and production technology, and almost disappears under standard functions. Our model is complementary to the model of Kiyotaki and Moore (1997) in that it reproduces a strong hump shape under standard settings. Moreover, it is a simplified version of the one used by Kiyotaki and Moore (2012), and the results derived are similar to their outcomes, which show that a liquidity shock can generate persistence and nonlinearity in the macroeconomic variables in a monetary model. Our model is also complementary to the one of Kiyotaki and Moore (2012) in that it indicates that the redistribution of wealth may be the key propagation mechanism that generates persistence and nonlinearity. ${ }^{1}$

The policy implications that flow from the results of standard DSGE and heterogeneous agent models may differ sharply. The standard DSGE model emphasizes that the cyclical movement of macroeconomic variables is the optimal response to shocks and thus that the stabilization of business cycles per se may not improve welfare significantly. ${ }^{2}$ Further, standard DSGE models note that the objective of macroeconomic policy is not the stabilization of business cycles, but rather the mitigation of inefficiency due to nominal rigidities. On the contrary, our heterogeneous agent model suggests that persistent recessions caused by financial shocks may be intrinsically inefficient due to credit constraints and endogenous wealth distribution, implying that corrective redistribution by government policy could improve aggregate efficiency and thus that the stabilization of

\footnotetext{
${ }^{1}$ One noticeable difference in the model settings is that while the productivity of an agent randomly changes in every period in Kiyotaki and Moore (2012), it follows a Markov process and thus is persistent in our model.

${ }^{2}$ This statement may not be rigorously true for Smets and Wouters (2003), in which the habit involves a consumption externality.
} 
aggregate variables per se may significantly improve welfare.

The remainder of this paper is organized as follows. A simplistic model is presented in Section 2 to demonstrate the basic mechanism of propagation due to the redistribution of wealth. In Section 3, we describe the generalized model in which capital depreciates partially and both long-term and short-term borrowings are subject to borrowing constraints. In Section 4, we analyze and compare the responses to a financial shock and a productivity shock. Section 5 concludes.

\section{Basic Model}

In this section, we present the workings of and analyze a simplistic model that is a version of Kiyotaki's (1998) model with only one modification: we make labor supply endogenous. ${ }^{3}$ The model presented herein is a closed economy with discrete time, inhabited by continua of workers and entrepreneurs. The measure of continua of workers and entrepreneurs is one. Both workers and entrepreneurs have the subjective discount factor $\beta(<1)$.

\section{$2.1 \quad$ Workers}

A unit mass of workers can save but cannot borrow. Based on Kiyotaki and Moore (2012), we assume that workers provide entrepreneurs with labor, and save and consume to maximize the following Greenwood-Hercowitz-Huffman utility function:

$$
E_{0} \sum_{t=0}^{\infty} \beta^{t} \ln \left[c_{t}^{\prime}-\frac{\omega}{1+\nu}\left(l_{t}\right)^{1+\nu}\right],
$$

subject to the budget constraint

$$
c_{t}^{\prime}+\frac{b_{t+1}^{\prime}}{r_{t}}=w_{t} l_{t}+b_{t}^{\prime}
$$

where $E_{0}$ denotes the expectation operator at time $0 ; c_{t}^{\prime}$ denotes consumption; $b_{t+1}^{\prime}$ is the bond, which is issued at time period $t$ and redeemed at $t+1 ; r_{t}$ is the gross interest rate; $w_{t}$ is the real wage rate; and $l_{t}$ is labor supply. The first-order conditions (FOCs) with

\footnotetext{
${ }^{3}$ Our model can also be considered to be a simplified version of those presented by Buera and Nicolini (2013) and Kiyotaki and Moore (2012).
} 
respect to consumption and labor indicate that labor supply is given by $l_{t}=\left(w_{t} / \omega\right)^{\frac{1}{\nu}}$. The FOC with respect to $b_{t+1}^{\prime}$ is as follows:

$$
\frac{x_{t+1}}{x_{t}} \geq \beta r_{t}
$$

and the non-negativity constraint is $b_{t+1}^{\prime} \geq 0$, where $x_{t}=c_{t}^{\prime}-\frac{\omega}{1+\nu}\left(l_{t}\right)^{1+\nu}$. If (3) holds with strict inequality, then $b_{t+1}^{\prime}=0$, and workers can be considered to be hand-to-mouth consumers who consume their entire income and do not save. Condition (3) implies that the condition for workers to be hand-to-mouth is as follows:

$$
\left(\frac{w_{t+1}}{w_{t}}\right)^{\frac{1+\nu}{\nu}}>\beta r_{t},
$$

which is satisfied for all the numerical simulations presented in this paper. ${ }^{4}$

\subsection{Entrepreneurs}

There is a unit mass of entrepreneurs. $n$ entrepreneurs have productivity $z$ and $1-n$ have productivity 1 , where $z>1$. We consider entrepreneurs with productivity $z$ to be high-productivity entrepreneurs (high entrepreneurs or high firms hereafter) and those with productivity 1 to be low-productivity entrepreneurs (low entrepreneurs or low firms hereafter). The terms "entrepreneur" and "firm" are used interchangeably throughout the paper. At the end of every period, $(1-\gamma) n$ high entrepreneurs are randomly chosen to become low entrepreneurs in the next period, and $(1-\gamma) n$ low entrepreneurs are randomly chosen to become high entrepreneurs in the next period. The entrepreneur's utility is as follows:

$$
E_{0} \sum_{t=0}^{\infty} \beta^{t} \ln c_{t},
$$

where $c_{t}$ is the entrepreneur's consumption. An entrepreneur with productivity $A_{t} \in\{1, z\}$ can produce output $y_{t}$ from labor $l_{t}$ and capital $k_{t}$ by using the following production technology:

$$
y_{t}=A_{t} k_{t}^{\alpha} l_{t}^{1-\alpha}
$$

\footnotetext{
${ }^{4}$ It is shown that at the steady state with binding borrowing constraints, the market interest rate satisfies $\beta r<1$. The gross interest rate $r$ is strictly less than $\beta^{-1}$ because the supply of bonds is smaller than that in the first best and therefore the bond price is higher.
} 
We assume that $A_{t}$ follows a Markov process, which is characterized by $\operatorname{Pr}(z \mid z)=\gamma, \operatorname{Pr}(1 \mid z)=$ $1-\gamma, \operatorname{Pr}(z \mid 1)=(1-\gamma) \frac{n}{1-n}, \operatorname{Pr}(1 \mid 1)=1-(1-\gamma) \frac{n}{1-n}$, where $\operatorname{Pr}(a \mid b)$ denotes the probability of $A_{t+1}=a$ conditional on $A_{t}=b$. We assume for analytical simplicity that capital stock $k_{t}$ fully depreciates after the production of output in this baseline model. The budget constraint for an entrepreneur is as follows:

$$
c_{t}+k_{t+1}-\frac{b_{t+1}}{r_{t}} \leq A_{t} k_{t}^{\alpha} l_{t}^{1-\alpha}-w_{t} l_{t}-b_{t}
$$

where $b_{t+1}$ is the bond issued in period $t$ and redeemed in period $t+1$. As workers do not save, only entrepreneurs hold the bonds issued by other entrepreneurs. When an entrepreneur purchases bonds issued by other entrepreneurs, $b_{t+1}$ can be a negative number. We consider the following assumption pertaining to a lack of commitment.

Assumption 1. An entrepreneur cannot commit to repay debt $\left(b_{t+1}\right)$. The creditors (or bond holders) can seize $\theta y_{t+1}$, where $y_{t+1}$ is output and $0<\theta<1$ if the entrepreneur repudiates his/her debt.

Under this assumption, a share of output $\left(\theta y_{t+1}\right)$ works as collateral for the debt and represents the upper limit of the amount that can be borrowed. Thus, the entrepreneur faces the following borrowing constraint:

$$
b_{t+1} \leq \theta A_{t+1} k_{t+1}^{\alpha} l_{t+1}^{1-\alpha},
$$

where $l_{t+1}$ is the labor input at $t+1$, which is decided in period $t+1$. As we see later in equation (8), $l_{t+1}$ is a linear function of $k_{t+1}$. After the revelation of $A_{t+1}$ at the end of period $t$, the entrepreneur with productivity $A_{t+1}$ chooses $\left\{c_{t}, k_{t+1}, b_{t+1}\right\}$ in period $t$ and $l_{t+1}$ in period $t+1$ to maximize his/her utility (5), subject to the budget constraint (6) and borrowing constraint (7).

\subsection{Benchmark without borrowing constraints}

The key determinant of aggregate dynamics in this economy is the entrepreneur's borrowing constraint. Here, we describe the dynamics in the case of no borrowing constraint. In an economy without borrowing constraints, entrepreneurs can borrow an unlimited 
amount. Thus, whereas high firms purchase all the capital stock and produce output at the equilibrium, low firms purchase the bonds issued by these firms, but do not produce output. The market interest rate is equal to the marginal product of capital for high firms.

Given that the capital stock of a high firm is $k_{t+1}$, the labor demand of this firm, $l_{t+1}$, is decided by the following equation:

$$
l_{t+1}=\arg \max z k_{t+1}^{\alpha} l_{t+1}^{1-\alpha}-w_{t+1} l_{t+1}=\left[\frac{(1-\alpha) z}{w_{t+1}}\right]^{\frac{1}{\alpha}} k_{t+1} .
$$

Thus, given the total amount of capital in the economy is $K_{t+1}$, total labor demand in period $t+1$ is $L_{t+1}^{d}=\left[\frac{(1-\alpha) z}{w_{t+1}}\right]^{\frac{1}{\alpha}} K_{t+1}$. As total labor supply is given by $L_{t+1}^{s}=\left(\frac{w_{t+1}}{\omega}\right)^{\frac{1}{\nu}}$ from the worker's optimization, labor market clearing can be indicated as follows: $w_{t+1}=$ $\left[(1-\alpha)^{\nu} z^{\nu} \omega^{\alpha} K_{t+1}^{\alpha \nu}\right]^{\frac{1}{\alpha+\nu}}$. The profit of a high firm, $\pi_{t+1}=z k_{t+1}^{\alpha} l_{t+1}^{1-\alpha}-w_{t+1} l_{t+1}$, can be written as $\pi\left(k_{t+1}, K_{t+1}\right)=r\left(K_{t+1}\right) k_{t+1}$, where

$$
r\left(K_{t+1}\right)=a K_{t+1}^{\phi-1}
$$

where $a=\alpha\left(\frac{1-\alpha}{\omega}\right)^{\frac{1-\alpha}{\alpha+\nu}} z^{\frac{1+\nu}{\alpha+\nu}}$ and $\phi=\frac{(1+\nu) \alpha}{\alpha+\nu}$.

The dynamics are described as follows. As workers are hand-to-mouth consumers, ${ }^{5}$ workers' consumption is given by the following equation:

$$
C_{t}^{\prime}=w_{t} L_{t}=\left[(1-\alpha)^{1+\nu} z^{1+\nu} \omega^{\alpha-1} K_{t}^{(1+\nu) \alpha}\right]^{\frac{1}{\alpha+\nu}},
$$

where $L_{t}$ is total labor. As the optimization problem for entrepreneurs is the BrockMirman model, they consume $1-\beta$ of total wealth, $W_{t}$, by the end of period $t$ and save $\beta W_{t}$. Thus,

$$
C_{t}=(1-\beta) W_{t}, \quad K_{t+1}=\beta W_{t}, \quad W_{t}=r\left(K_{t}\right) K_{t} .
$$

These equations indicate the evolution of capital stock as follows:

$$
K_{t+1}=a \beta K_{t}^{\phi}
$$

\footnotetext{
${ }^{5}$ As (4) is not satisfied at the equilibrium where no borrowing constraint exists, it is not possible to assess whether workers are hand-to-mouth from the workers' optimization. However, here we have made this assumption for simplicity.
} 
Figure 1: Equilibrium path without borrowing constraints
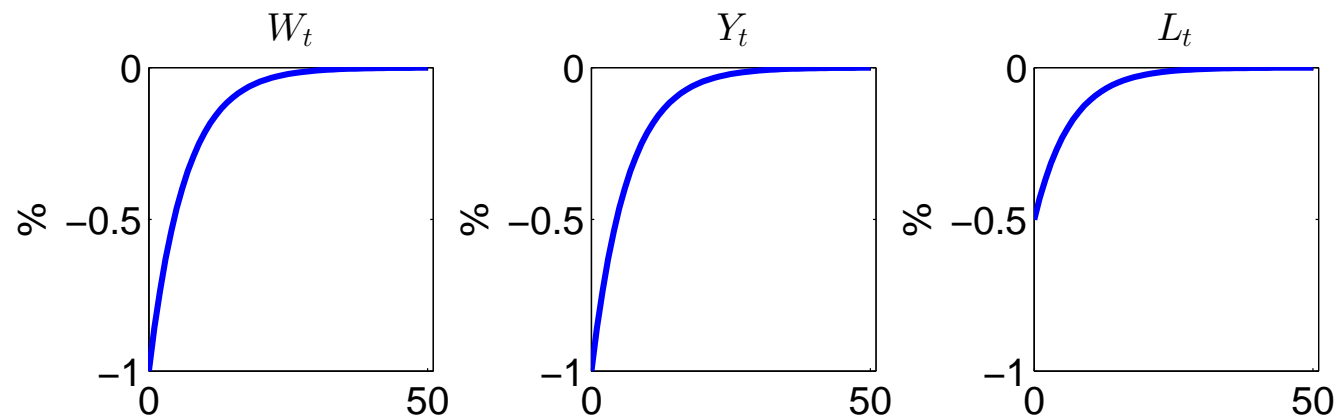

Notes 1. Percentage deviations from the steady state are shown.

2. Convergence time is 31 periods. We judge convergence when the deviation is less than $0.01 \%$.

Numerical example: The equilibrium path from the initial wealth $W_{0}\left(<W^{*}\right)$ is shown in Figure 1. Figure 1 shows the equilibrium paths of wealth $\left(W_{t}\right)$, output $\left(Y_{t}\right)$, and labor $\left(L_{t}\right)$. The parameter values are $\alpha=0.75, \beta=0.98, \nu=1, \theta=0.3, z=$ 1.1, $\gamma=0.9, n=0.1, \omega=1$. Since we focus on the qualitative features of the model, we do not calibrate these parameter values. We also consider a large value for $\alpha$ since we interpret output as including the remaining capital stock. The initial $W_{0}$ is adjusted such that output in period 0 is lower than the steady-state value by $1 \%$. As the variables quickly converge to the steady state following dynamics similar to those of the Solow model, persistence and hump shape are not observed.

\subsection{Dynamics of the economy with binding borrowing constraints}

In an economy with borrowing constraints (7), high firms cannot issue a sufficient amount of bonds and as a result, they cannot use all the capital stock in the economy. With a sufficiently tight borrowing constraint, low firms also use capital and produce output by utilizing their inferior technology. This situation gives rise to the particular type of equilibrium analyzed next. As low firms are typically indifferent between purchasing capital and purchasing the bonds issued by high firms, returns from investment at $k_{t+1}$ and $b_{t+1}$ should be identical at the equilibrium in this case. Thus,

$$
r_{t}=\alpha\left(\frac{1-\alpha}{w_{t+1}}\right)^{\frac{1-\alpha}{\alpha}}
$$


Next, we calculate the rate of return on investment for high entrepreneurs. The profit of a high entrepreneur who has $k_{t+1}$ units of capital stock is expressed as follows:

$$
\pi\left(k_{t+1}, w_{t+1}\right)=\max _{l} z k_{t+1}^{\alpha} l^{1-\alpha}-w_{t+1} l=\alpha z^{\frac{1}{\alpha}}\left(\frac{1-\alpha}{w_{t+1}}\right)^{\frac{1-\alpha}{\alpha}} k_{t+1} .
$$

Suppose the wealth of a high entrepreneur is $a_{t}$. He/she consumes $c_{t}$ and invests $a_{t}-c_{t}$ in capital stock. Additionally, he/she can issue bonds to increase his/her capital stock to $k_{t+1}$. The entrepreneur chooses $\left\{b_{t+1}, k_{t+1}\right\}$ to maximize $a_{t+1}=\pi\left(k_{t+1}, w_{t+1}\right)-b_{t+1}$. The optimization problem can thus be written as follows:

$$
\begin{aligned}
& \max _{k_{t+1}, b_{t+1}} \pi\left(k_{t+1}, w_{t+1}\right)-b_{t+1}, \\
& \text { subject to }\left\{\begin{array}{l}
k_{t+1}=a_{t}-c_{t}+\frac{b_{t+1}}{r_{t}}, \\
b_{t+1} \leq \theta z k_{t+1}^{\alpha} l_{t+1}^{1-\alpha} .
\end{array}\right.
\end{aligned}
$$

The solution for this problem, combined with (10), implies the following dynamics of $\left\{k_{t+1}, a_{t+1}\right\}:$

$$
\begin{aligned}
& k_{t+1}=\hat{k}\left(a_{t}-c_{t}\right), \\
& a_{t+1}=R_{t}\left(a_{t}-c_{t}\right),
\end{aligned}
$$

where

$$
\begin{aligned}
& \hat{k}=\frac{1}{1-\frac{\theta}{\alpha} z^{\frac{1}{\alpha}}}, \\
& R_{t}=\left(1-\frac{\theta}{\alpha}\right) z^{\frac{1}{\alpha}} r_{t} \hat{k} .
\end{aligned}
$$

The reduced form of the optimization problem for a high entrepreneur is as follows:

$$
\begin{aligned}
& \max _{c_{t}} E_{t} \sum_{s=0}^{\infty} \beta^{s} \ln c_{t+s}, \\
& \text { subject to } a_{t+1}=R_{t}\left(a_{t}-c_{t}\right) .
\end{aligned}
$$

The reduced form of the problem for a low entrepreneur is as follows:

$$
\begin{aligned}
& \max _{c_{t}} E_{t} \sum_{s=0}^{\infty} \beta^{s} \ln c_{t+s}, \\
& \text { subject to } a_{t+1}=r_{t}\left(a_{t}-c_{t}\right) .
\end{aligned}
$$


These optimizations are the same as those in the Brock-Mirman model, where entrepreneurs consume $(1-\beta) a_{t}$ and save $\beta a_{t}$. By denoting the wealth of entrepreneur $i$ by $a_{i t}$, where $i \in[0,1]$, the total wealth in this economy is defined as follows:

$$
W_{t}=\int_{0}^{1} a_{i t} d i
$$

Furthermore, we denote the wealth owned by high entrepreneurs by $s_{t} W_{t}$, where $s_{t} \in[0,1]$ is the share of the wealth of high entrepreneurs. The aggregate dynamics of the economy are decided by the evolution of the two state variables $\left\{s_{t}, W_{t}\right\}$, as shown below. First, the total consumption of entrepreneurs is expressed as follows:

$$
C_{t}=(1-\beta) W_{t} .
$$

As workers are hand-to-mouth, ${ }^{6}$ total capital stock is as follows:

$$
K_{t+1}=\beta W_{t} .
$$

We denote the total capital stock used by high entrepreneurs as $\hat{K}_{t+1}$ and that by low entrepreneurs as $K_{t+1}^{\prime}=K_{t+1}-\hat{K}_{t+1}$. (11) implies

$$
\begin{aligned}
\hat{K}_{t+1} & =\tilde{k}\left(s_{t}\right) \beta W_{t}, \\
K_{t+1}^{\prime} & =\left(1-\tilde{k}\left(s_{t}\right)\right) \beta W_{t},
\end{aligned}
$$

where $\tilde{k}\left(s_{t}\right)=\min \left\{1, \hat{k} s_{t}\right\}$. Similarly, we denote the total labor used by high entrepreneurs as $\hat{L}_{t+1}$ and that by low entrepreneurs as $L_{t+1}^{\prime}$.

$$
\begin{aligned}
\hat{L}_{t+1} & =z^{\frac{1}{\alpha}}\left(\frac{1-\alpha}{w_{t+1}}\right)^{\frac{1}{\alpha}} \hat{K}_{t+1}, \\
L_{t+1}^{\prime} & =\left(\frac{1-\alpha}{w_{t+1}}\right)^{\frac{1}{\alpha}} K_{t+1}^{\prime} .
\end{aligned}
$$

Labor market clearing $\left(L_{t+1}=\hat{L}_{t+1}+L_{t+1}^{\prime}\right)$ determines the following wage rate:

$$
w_{t+1}=\left[1+\left(z^{\frac{1}{\alpha}}-1\right) \tilde{k}\left(s_{t}\right)\right]^{\frac{\alpha \nu}{\alpha+\nu}}(1-\alpha)^{\frac{\nu}{\alpha+\nu}} \omega^{\frac{\alpha}{\alpha+\nu}}\left(\beta W_{t}\right)^{\frac{\alpha \nu}{\alpha+\nu}} .
$$

\footnotetext{
${ }^{6}$ We assume that (4) holds and justify later in the numerical experiment that (4) actually holds on the equilibrium path.
} 
The market interest rate is determined as a function of $\left(s_{t}, W_{t}\right)$, according to (10), and $R_{t}$ is given by (13). ${ }^{7}$ The total output produced by high entrepreneurs is $\hat{Y}_{t+1}=z \hat{K}_{t+1}^{\alpha} \hat{L}_{t+1}^{1-\alpha}$ and that by low entrepreneurs is $Y_{t+1}^{\prime}=\left(K_{t+1}^{\prime}\right)^{\alpha}\left(L_{t+1}^{\prime}\right)^{1-\alpha}$. Finally, we can decide the evolution of $\left(s_{t+1}, W_{t+1}\right)$. As the rate of return for high firms is $R_{t}$ and that for low firms is $r_{t}$, wealth in the next period, $W_{t+1}$, evolves based on the following expression:

$$
W_{t+1}=\left[R_{t} s_{t}+r_{t}\left(1-s_{t}\right)\right] \beta W_{t} .
$$

High entrepreneurs in period $t$ obtain $R_{t} s_{t} \beta W_{t}$ in the next period and survive with probability $\gamma$. Thus, the total wealth of surviving high entrepreneurs is $\gamma R_{t} s_{t} \beta W_{t}$. As the per capita wealth of a low entrepreneur is $\frac{\left(1-s_{t}\right) r_{t} \beta W_{t}}{1-n}$, the total wealth of high entrepreneurs who were previously low entrepreneurs is $(1-\gamma) n \times \frac{\left(1-s_{t}\right) r_{t} \beta W_{t}}{1-n}$. Thus, the share of wealth owned by high entrepreneurs in period $t+1$ is given by the following:

$$
s_{t+1} W_{t+1}=\left\{\gamma R_{t} s_{t}+(1-\gamma) \frac{n}{1-n}\left(1-s_{t}\right) r_{t}\right\} \beta W_{t} .
$$

Assuming that $\tilde{k}\left(s_{t}\right)=\hat{k} s_{t}<1$ always holds, (15) and (16) imply the following law of motion for the state variables:

$$
\begin{aligned}
& W_{t+1}=\left[1+\left\{z^{\frac{1}{\alpha}}-1\right\} \hat{k} s_{t}\right] r_{t} \beta W_{t}, \\
& s_{t+1}=\frac{\gamma\left(1-\frac{\theta}{\alpha}\right) z^{\frac{1}{\alpha}} \hat{k} s_{t}+(1-\gamma) \frac{n}{1-n}\left[1-s_{t}\right]}{1+\left(z^{\frac{1}{\alpha}}-1\right) \hat{k} s_{t}} .
\end{aligned}
$$

This completes the description of the dynamics. In the numerical simulation, we calculate EW and LW based on the BCA method.

- EW:

$$
E W_{t}=\frac{\left(\hat{Y}_{t}+Y_{t}^{\prime}\right)}{K_{t}^{\alpha} L_{t}^{1-\alpha}}
$$

- LW:

$$
L W_{t}=\frac{w_{t}}{(1-\alpha) \frac{\left(\hat{Y}_{t}+Y_{t}^{\prime}\right)}{L_{t}}} .
$$

\footnotetext{
${ }^{7}$ Note that in the case when $\tilde{k}\left(s_{t}\right)=1$, low entrepreneurs do not produce output. Thus, $R_{t}=z^{\frac{1}{\alpha}} r_{t}$ and the market rate are equal to $R_{t}$.
} 


\subsubsection{Redistribution of wealth and equilibrium dynamics}

We now consider the dynamic response of the economy to deviations in the two state variables, $\left(W_{t}, s_{t}\right)$. A change in $s_{t}$ mostly represents the redistribution of wealth. In this economy, high firms are borrowers and low firms are lenders. Redistribution, namely a change in $s_{t}$, is a change in the net worth of borrowers. The effect of borrowers' net worth on the aggregate dynamics has been analyzed by Bernanke and Gertler (1989) and Bernanke et al. (1999). As Bernanke and Gertler (1989) point out, redistribution can represent "debt deflation," because an unexpected decline in prices transfers wealth from borrowers to lenders. Similarly, the emergence and collapse of the asset-price bubble could be an example of the redistribution of wealth in an economy where assets are used as collateral, since asset-price bubbles increase the loan amount and the subsequent bubble collapse decreases the net worth of borrowers.

We set the parameters at the same values as those in Section 2.3: $\alpha=0.75, \beta=$ $0.98, \nu=1, \theta=0.3, z=1.1, \gamma=0.9, n=0.1, \omega=1$. We assume that the economy is initially at the steady-state equilibrium. The solid line in Figure 2 represents the response to a decrease in $W_{0}$. The value of $W_{0}$ is chosen such that output in period 0 decreases by $1 \%$ from the steady state. Similarly, the solid line in Figure 3 shows the response to a decrease in $s_{0}$. The value of $s_{0}$ is chosen such that output in period 0 decreases by $1 \%$ from the steady state.

Figure 2 shows that the dynamic response of the economy to a $W_{t}$ shock is qualitatively the same as that in the case without borrowing constraints (Figure 1). In this case, $s_{t}$ and the two wedges $\left(E W_{t}\right.$ and $\left.L W_{t}\right)$ are invariant over time.

Figure 3 shows that the response to a $s_{t}$ shock displays remarkable persistence compared with a $W_{t}$ shock: the convergence time in Figure 3 is twice as long as that in Figure 2. Figure 3 shows that the responses of output (which is proportional to consumption and investment) and labor are conspicuously hump-shaped. It is quite rare for a model with such a simple structure to reproduce strong hump-shaped responses. On the contrary, the response to the redistribution of wealth in Carlstrom and Fuerst (1997), Bernanke and Gertler (1989), and Bernanke et al. (1999) is weakly hump-shaped. 
Figure 2: Response to a $W_{t}$ shock
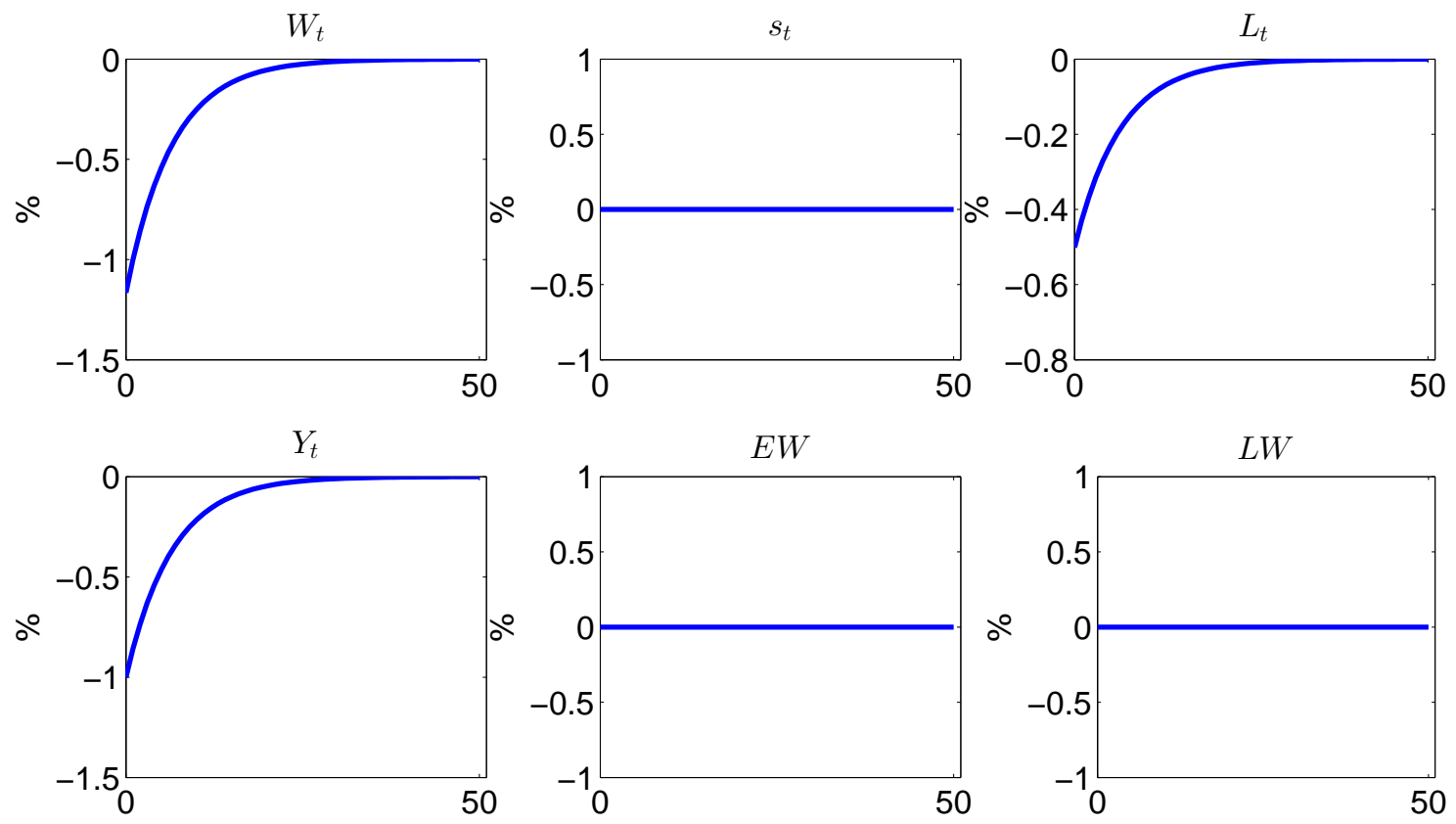

Notes 1. Percentage deviations from the steady state are shown.

2. Convergence time is 31 periods. We judge convergence when the deviation is less than $0.01 \%$.

The intuition of the results shown in Figures 2 and 3 can be understood from (17) and (18). As equation (18) shows, a change in $W_{t}$ does not affect $s_{t}$ and the only effect is a proportional change in the capital stock for both high and low firms. Therefore, the effect of a $W_{t}$ shock in the basic model with borrowing constraints is the same as that without borrowing constraints.

The strongly persistent and hump-shaped response to a $s_{t}$ shock is generated from the dependence of $W_{t}$ on $s_{t}$. Equation (18) indicates that $s_{t}$ monotonically converges from the initial value, $s_{0}$, to the steady-state value, $s^{*}$. On the contrary, equations (10), (14), and (17) imply that

$$
W_{t+1}=\alpha\left(\frac{1-\alpha}{\alpha+\nu}\right)^{\frac{1-\alpha}{\alpha+\nu}}\left[\left\{1+\left(z^{\frac{1}{\alpha}}-1\right) \hat{k} s_{t}\right\} \beta W_{t}\right]^{\phi} .
$$

Since $0<\phi<1$, the gross rate of wealth growth $\left(W_{t+1} / W_{t}\right)$ is increasing in $s_{t}$ and decreasing in $W_{t}$. When $s_{t}$ sufficiently deviates from $s^{*}$, the negative effect of $s_{t}$ on the 
Figure 3: Response to a $s_{t}$ shock
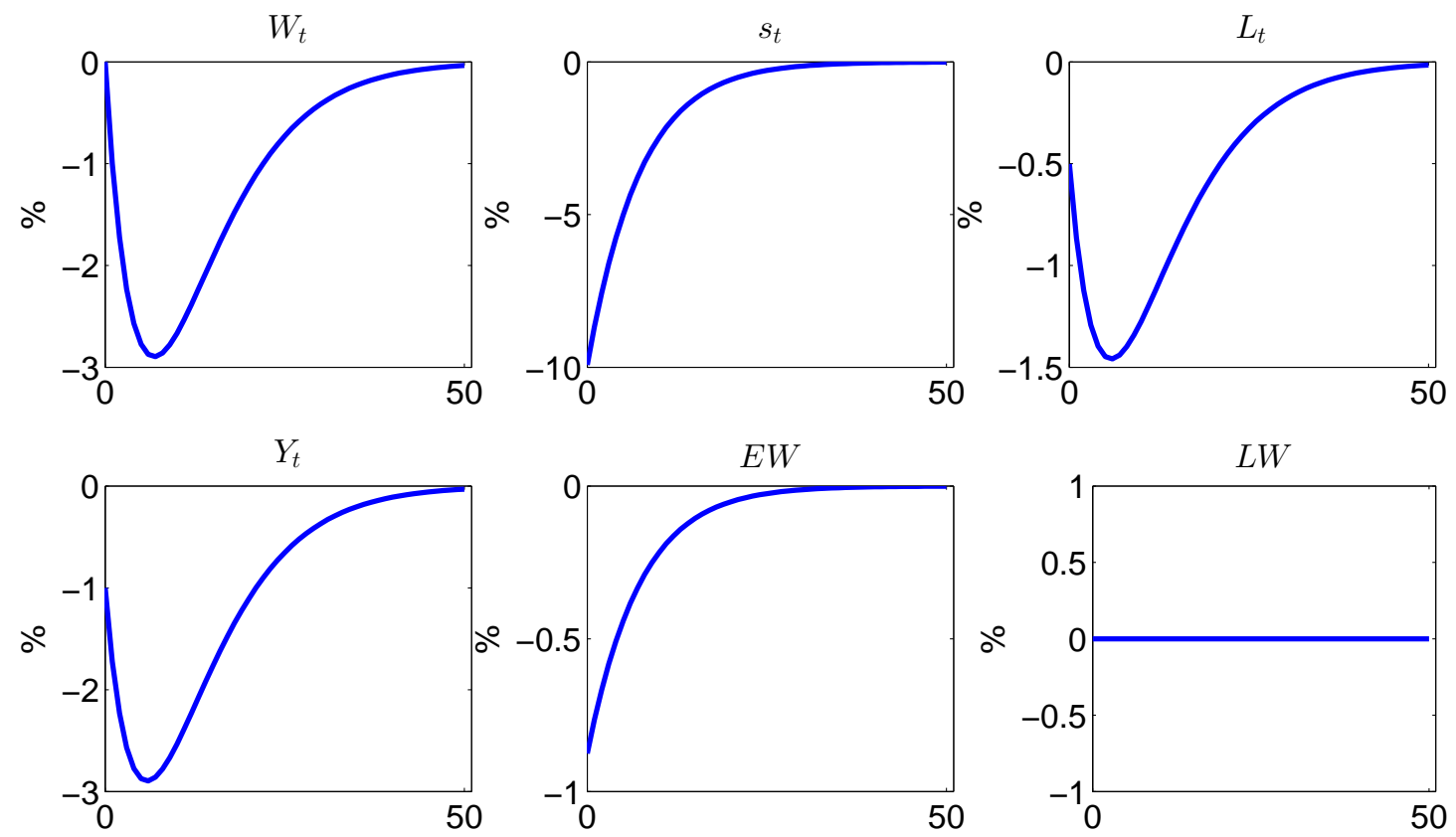

Notes 1. Percentage deviations from the steady state are shown.

2. Convergence time is 60 periods. We judge convergence when the deviation is less than $0.01 \%$.

growth of wealth is dominant and $W_{t+1}$ deviates further from $W^{*}$, whereas when $s_{t}$ goes back to a sufficiently close neighborhood of $s^{*}$, the positive effect of $W_{t}$ on the growth of wealth becomes dominant and $W_{t+1}$ starts converging to $W^{*}$. In this way, $W_{t}$ diverges from $W^{*}$ immediately after the redistribution and starts converging to $W^{*}$ several periods later. ${ }^{8}$ This fact explains the presence of the persistent and hump-shaped response. The response of $E W_{t}$ is procyclical and consistent with the observations of a long recession such as the Great Depression in the United States.

Note that the original model in Kiyotaki (1998), in which labor supply is fixed, does not display a hump-shaped response to a redistribution shock, whereas the current model does. The finding of this paper is thus that the endogeneity of the labor input can significantly amplify the shock.

\footnotetext{
${ }^{8}$ Persistence and hump shape in the aggregate variables are sensitive to the parameter values. For example, when $\alpha=0.4$ in the basic model, the persistence and hump shape disappear in response to a change in $s_{t}$.
} 


\section{Generalized model}

\subsection{Setting}

The assumption of complete capital stock depreciation in one period enables us to describe the dynamics of the model by using two equations, (17) and (18), and thus understand the workings of the model analytically. This assumption is unrealistic, however.

To confirm whether our results hold in a general setting, we modify our model in such a way that capital depreciates partially. In the generalized model, we set the depreciation rate of capital, $\delta$, as 0.03 and consider that a share of the remaining capital stock works as the collateral for borrowing. We use more standard values for the parameters: $\alpha=0.3, \beta=0.98, \delta=0.03, \gamma=0.99, \nu=1, \theta=0.3, z=1.1, n=0.1, \omega=1$. In reality, firms are not only constrained when borrowing long-term loans or issuing longterm bonds to finance capital expenditure, but also when borrowing short-term loans to finance working capital expenditure such as wage payments and the purchase of material and intermediate goods. The borrowing constraints on short-term loans or working capital loans have been comprehensively analyzed by recent studies (e.g., Mendoza, 2010; Kobayashi, Nakajima and Inaba, 2012; Jermann and Quadrini, 2012). These authors have shown that the borrowing constraint on short-term loans, especially for wage payments, can generate fluctuations in LW (Kobayashi et al., 2012). Moreover, LW is time-invariant in the models presented in the previous section, as there is no friction in the demand and supply of labor inputs. In this section, we numerically check whether a deterioration in LW during a recession can be reproduced in our model by introducing borrowing constraints on short-term loans.

We assume that the optimization problem for an entrepreneur is written as follows:

$$
\begin{array}{cl}
\max E_{t} & \sum_{s=0}^{\infty} \beta^{s} \ln c_{t+s} \\
\text { subject to } & c_{t}+k_{t+1}-\frac{b_{t+1}}{r_{t}} \leq y_{t}-w_{t} l_{t}-b_{t}+(1-\delta) k_{t}, \\
\text { and } & w_{t+1} l_{t+1}+b_{t+1} \leq \theta k_{t+1} .
\end{array}
$$

The second constraint is the borrowing constraint that depicts that the entrepreneur can- 
not pay wages to his/her workers before the completion of production. The entrepreneur is obligated to pay wages to his/her workers and redeem the bonds issued in the previous period after production. In other words, workers who worked for the entrepreneur in period $t+1$ have a claim over $w_{t+1} l_{t+1}$ after the completion of production in period $t+1$. However, there is a possibility that the entrepreneur absconds without paying wages and redeeming the bonds (limited commitment). We assume here that creditors may seize $\theta k_{t}$ in the case of default, meaning that the entrepreneur has an upper limit of debt, which is given by (22). This constraint affects the borrowing twice. In period $t+1$, given the prefixed amount of $b_{t+1}$, the constraint (22) limits the short-term loan $w_{t+1} l_{t+1}$. In period $t$, given the (expected) amount of $l_{t+1}=l_{t+1}\left(b_{t+1}\right)$ to be chosen at $t+1,(22)$ limits the amount of borrowing, $b_{t+1}$. Therefore, in the modified model discussed in this section, an entrepreneur chooses $\left\{c_{t}, k_{t+1}, b_{t+1}, l_{t+1}\right\}$ to maximize (20), subject to the budget constraint (21) and borrowing constraint (22).

\subsection{Dynamics}

Similar arguments in the case of the equilibrium, at which both high and low firms operate, imply that the market interest rate is given by

$$
r_{t}=\alpha\left(\frac{1-\alpha}{w_{t+1}}\right)^{\frac{1-\alpha}{\alpha}}+1-\delta .
$$

In this case, the high entrepreneur's optimization is solved as follows. ${ }^{9}$ The variables $\left\{c_{t}, k_{t+1}, b_{t+1}, l_{t+1}\right\}$ are determined backwards. First, $l_{t+1}$ is chosen in period $t+1$, given the other three variables; second, $k_{t+1}$ and $b_{t+1}$ are chosen in period $t$, given the (expected) value of $l_{t+1}$ and the prefixed value of $c_{t}$; and third, $c_{t}$ is chosen in period $t$, given the (expected) values of the other three variables.

The first step for high firms involves solving the following:

$$
\begin{aligned}
& \max _{l_{t+1}} z k_{t+1}^{\alpha} l_{t+1}^{1-\alpha}-w_{t+1} l_{t+1}, \\
& \text { s. t. } \quad w_{t+1} l_{t+1}+b_{t+1} \leq \theta k_{t+1} .
\end{aligned}
$$

\footnotetext{
${ }^{9}$ This analysis is a slight modification of that in Kiyotaki (1998).
} 
We denote the Lagrange multiplier by $\mu$ and will solve this soon. The FOC indicates that labor demand is as follows:

$$
l_{t+1}=l\left(\mu, k_{t+1}\right) \equiv\left[\frac{(1-\alpha) z}{(1+\mu) w_{t+1}}\right]^{\frac{1}{\alpha}} k_{t+1} .
$$

The second problem is written as follows, given labor demand $l\left(\mu, k_{t+1}\right)$, consumption $c_{t}$, and wealth $a_{t}$ :

$$
\begin{aligned}
& \max _{\mu, k_{t+1}, b_{t+1}} a_{t+1}, \\
& \text { s. t. }\left\{\begin{array}{l}
k_{t+1} \leq a_{t}-c_{t}+\frac{b_{t+1}}{r_{t}}, \\
b_{t+1} \leq \theta k_{t+1}-w_{t+1} l_{t+1}, \\
a_{t} \equiv z k_{t}^{\alpha} l_{t}^{1-\alpha}-w_{t} l_{t}-b_{t}+(1-\delta) k_{t} .
\end{array}\right.
\end{aligned}
$$

This problem is further simplified to the following for the variable $x \equiv\left[\frac{1-\alpha}{(1+\mu) w_{t+1}}\right]^{\frac{1}{\alpha}}$ :

$$
\begin{aligned}
& \max _{x} R_{t}(x) \times\left\{a_{t}-c_{t}\right\} \\
& \text { where } R_{t}(x) \equiv \frac{z^{\frac{1}{\alpha}} x^{1-\alpha}+1-\delta-\theta}{1-\frac{\theta}{r_{t}}+\frac{w_{t+1}}{r_{t}} x z^{\frac{1}{\alpha}}} .
\end{aligned}
$$

The FOC is

$$
(1-\alpha) x^{-\alpha}\left(r_{t}-\theta+z^{\frac{1}{\alpha}} x_{t} w_{t+1}\right)=w_{t+1}\left\{z^{\frac{1}{\alpha}} x^{1-\alpha}+1-\theta-\delta\right\} .
$$

The third problem, or the consumption choice by the high entrepreneur, is $\max _{c_{t}} E_{t} \sum_{s=0}^{\infty} \beta^{s} \ln c_{t+s}$, subject to $a_{t+1}=R_{t}\left(a_{t}-c_{t}\right)$, while the problem for the low entrepreneur is also $\max _{c_{t}} E_{t} \sum_{s=0}^{\infty} \beta^{s} \ln c_{t+s}$, subject to $a_{t+1}=r_{t}\left(a_{t}-c_{t}\right)$, both of which are from the Brock-Mirman model. The solution is $c_{t}=\beta a_{t}$.

The aggregate dynamics are similar to those presented in Section 2.4. Total consumption by entrepreneurs is $C_{t}=(1-\beta) W_{t}$ and total capital stock is $K_{t+1}=\beta W_{t}$. Thus,

$$
\begin{aligned}
\hat{K}_{t+1} & =\frac{\beta s_{t} W_{t}}{1-\frac{\theta-z^{\frac{1}{\alpha}} x_{t} w_{t+1}}{r_{t}}}, \\
K_{t+1}^{\prime} & =\beta W_{t}-\hat{K}_{t+1} .
\end{aligned}
$$


Here, we assume that $\hat{K}_{t+1}<K_{t+1}$ always holds. ${ }^{10}$ Labor demands are as follows:

$$
\hat{L}_{t+1}=z^{\frac{1}{\alpha}} x_{t} \hat{K}_{t+1}, \quad \quad L_{t+1}^{\prime}=\left(\frac{1-\alpha}{w_{t+1}}\right)^{\frac{1}{\alpha}} K_{t+1}^{\prime} .
$$

High firms produce $\hat{Y}_{t+1}=z^{\frac{1}{\alpha}} x_{t}^{1-\alpha} \hat{K}_{t+1}$ and low firms produce $Y_{t+1}^{\prime}=\left(\frac{1-\alpha}{w_{t+1}}\right)^{\frac{1-\alpha}{\alpha}} K_{t+1}^{\prime}$. Labor market clearing $\left(L_{t+1}=\hat{L}_{t+1}+L_{t+1}^{\prime}\right)$ implies that

$$
\left(\frac{w_{t+1}}{\omega}\right)^{\frac{1}{\nu}}=z^{\frac{1}{\alpha}} x_{t} \hat{K}_{t+1}+\left(\frac{1-\alpha}{w_{t+1}}\right)^{\frac{1}{\alpha}} K_{t+1}^{\prime} .
$$

The variables $\left\{w_{t+1}, x_{t}, r_{t}\right\}$ can be determined numerically as functions of $\left(s_{t}, W_{t}\right)$ by using equations (23), (24), and (25). The trend of the state variables $\left(s_{t}, W_{t}\right)$ is governed by the following:

$$
\begin{aligned}
& W_{t+1}=\left\{R_{t} s_{t}+\left(1-s_{t}\right) r_{t}\right\} \beta W_{t}, \\
& s_{t+1}=\left\{\gamma R_{t} s_{t}+(1-\gamma) \frac{n}{1-n}\left(1-s_{t}\right) r_{t}\right\} \frac{\beta W_{t}}{W_{t+1}} .
\end{aligned}
$$

This completes the description of the dynamics. ${ }^{11}$

\subsection{Numerical calculation}

Here, we use the parameter values given in Section 3.1, which make the borrowing constraint binding at the steady state. As expected, the responses of output and labor to a decrease in $W_{0}$ are not hump-shaped. ${ }^{12}$ Figure 4 shows the dynamics when the initial value of the wealth share, $s_{0}$, is not equal to $s^{*}$, where $s^{*}$ is the steady-state value. The value of $s_{0}$ is chosen such that output in period 0 is lower by $1 \%$ than the steady-state value. Output and labor display conspicuously hump-shaped and persistent responses. An interesting result is that $L W_{t}$ varies over time. In other words, $L W$ improves in response

\footnotetext{
${ }^{10}$ The dynamics in the case where $\hat{K}_{t+1}=K_{t+1}$ are the same as those in the basic model in Section 2.3 , because when $\hat{K}_{t+1}=K_{t+1}$, the borrowing constraint does not bind in either model.

${ }^{11}$ Note that we assume that

$$
\frac{s_{t}}{1-\frac{\theta-z^{\frac{1}{\alpha}} x_{t} w_{t+1}}{r_{t}}}<1
$$

The dynamics in the case where the above inequality does not hold are described in the appendix.

${ }^{12}$ The numerical result for a $W_{t}$ shock is not reported in this paper. The result is available from the authors upon request.
} 
Figure 4: Dynamics with an initial $s_{0}$ smaller than the steady-state value
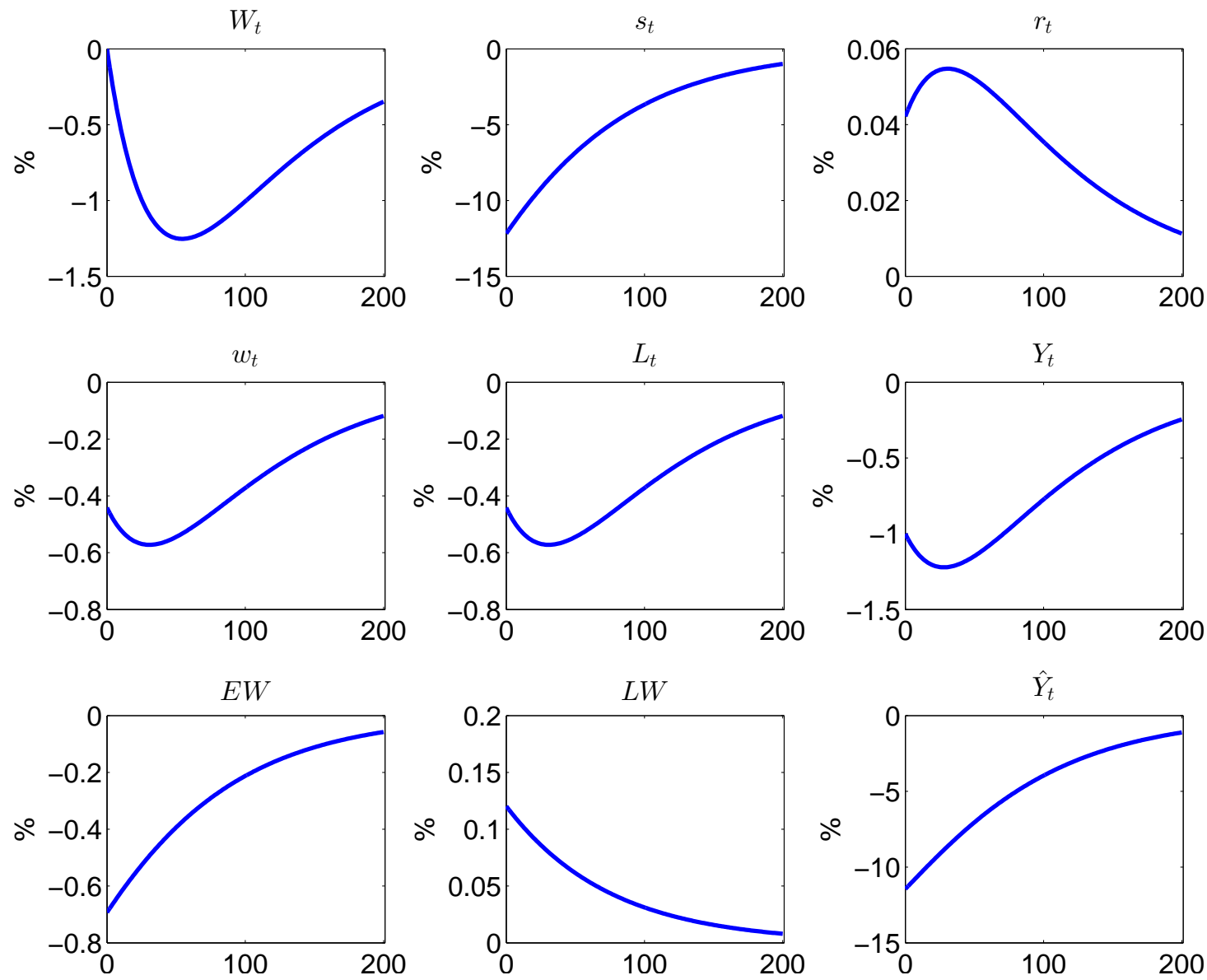

Notes 1. Percentage deviations from the initial steady state are shown.

2. Convergence time is 444 periods. We judge convergence when the deviation is less than $0.01 \%$.

to a decrease in output. This result is opposite to that observed in previous empirical studies. ${ }^{13}$

Our results indicate that reproducing procyclicality in LW remains a significant challenge for macroeconomics research (see for example, Arellano, Bai and Kehoe, 2012; Pesca-

\footnotetext{
${ }^{13}$ The intuition behind the improvement in LW can be described as follows. The redistribution of wealth from high firms to low firms exogenously decreases intertemporal debt $\left(b_{t+1}\right)$ and capital $\left(\hat{K}_{t}\right)$ for high firms and thus lowers labor demand by high firms. As a result, total labor demand decreases and the wage rate decreases, too. There are two competing effects on LW: (i) decreases in both the labor demand of high firms and the wage rate relax the borrowing constraint and improve LW and (ii) a decrease in the net worth of high firms due to the redistribution tightens the borrowing constraint and deteriorates LW. We confirm that the total effect improves LW in this numerical example.
} 
tori and Tasci, 2011). ${ }^{14}$

\section{Propagation of financial and productivity shocks}

In this section, we show numerically the response of the economy to exogenous shocks (i.e., productivity shocks and financial shocks). It is shown in this model that the redistribution of wealth among heterogeneous agents is crucial to generating hump-shaped and persistent responses to financial shocks.

\subsection{Responses with binding borrowing constraints}

We assume the same parameter values as those in Section 3. Note that as $\theta=0.3$, the borrowing constraint for high firms is always binding in our numerical simulation.

Productivity shocks: The solid lines in Figure 5 show the response of the economy to a productivity shock $\left(z_{t}, \zeta_{t}\right)$, where $\zeta_{t}$ is the productivity of low firms, the value of which is 1 at the steady state. We assume that the economy was initially at the steady state and that the shock lowers the initial values of $\left(z_{0}, \zeta_{0}\right)$ below their steady-state values by the same ratio, in such a way that output at time 0 is lower than its steady-state value by $1 \%$. We assume that $\left(z_{t}, \zeta_{t}\right)$ evolves by $z_{t}=\rho z_{t-1}+(1-\rho) z^{*}$ and $\zeta_{t}=\rho \zeta_{t-1}+(1-\rho) \zeta^{*}$, with $\rho=0.965$, for $t \geq 1$. As expected, there is no hump shape in the paths of either output or labor. The dotted lines in Figure 5 show the case with the presence of a transfer policy, in which the government makes a lump-sum transfer between high and low firms in such a way that $s_{t}=s^{*}$ for all $t$. This figure shows that there is no significant difference between the solid lines and dotted lines. We can thus summarize the effects of the productivity shock as follows:

- The productivity shock does not generate a hump-shaped response.

\footnotetext{
${ }^{14}$ One referee suggested that a model of borrowing-constrained workers à la Campbell and Hercowitz $(2009,2011)$ could reproduce procyclical LW. As our focus in this paper is on the borrowing constraint on firms, we leave this line of research for a future study.
} 
- Wealth share does not play a significant role in amplifying the effect of the productivity shock.

Here, we note that a weakly hump-shaped response may be generated by the productivity shock for a specific set of parameter values. The fact that the productivity shock can generate a hump-shaped response is sometimes found in business cycle models, although it is not typically emphasized in the literature. For example, Shirai (2014) shows that a simple Real Business Cycle (RBC) model with standard parameter values displays a weakly hump-shaped response to a productivity shock when the shock is sufficiently persistent $(\rho=0.99)$. Shirai's result is notable in that it shows that a simple RBC model without habit persistence or adjustment costs of investment can display a hump-shaped response. ${ }^{15}$

Financial shocks: The solid lines in Figure 6 show the response of the economy to a shock on $\theta_{t}$, which is called a "financial shock" in Jermann and Quadrini (2012). We assume that the economy was initially at the steady state and that the shock lowers the initial values of $\theta_{0}$ below their steady-state values, in such a way that output at time 0 is lower than its steady-state value by $1 \%$. We assume that $\theta_{t}$ evolves by $\theta_{t}=\rho \theta_{t-1}+(1-\rho) \theta^{*}$, with $\rho=0.965$, for $t \geq 1$. Output and labor show conspicuously persistent and humpshaped responses to the financial shock. Output hits the bottom of the hump at $t=16$ when $Y_{t}$ is lower than $Y^{*}$ by $1.1 \%$. By contrast, labor hits the bottom of the hump at $t=23$ when $L_{t}$ is lower than $L^{*}$ by $0.47 \%$. The dotted lines in Figure 6 show the case with the transfer policy, in which the government makes a lump-sum transfer between high firms and low firms in such a way that $s_{t}=s^{*}$ for all $t$. The dotted lines imply that the humps and persistence are significantly weakened under the transfer policy. We can summarize the effects of the financial shock as follows:

- The financial shock generates a conspicuously persistent and hump-shaped response.

- Wealth redistribution, namely changes in $s_{t}$, amplifies the persistence and hump shape in output and labor significantly.

\footnotetext{
${ }^{15}$ Romer (2011) describes that, under the assumption of the full depreciation of capital, the RBC model is reduced to the Brock-Mirman model and thus shows a hump-shaped response to a productivity shock.
} 
Figure 5: Response to a macro technology shock ( $z_{t}$ and $\zeta_{t}$ shocks)
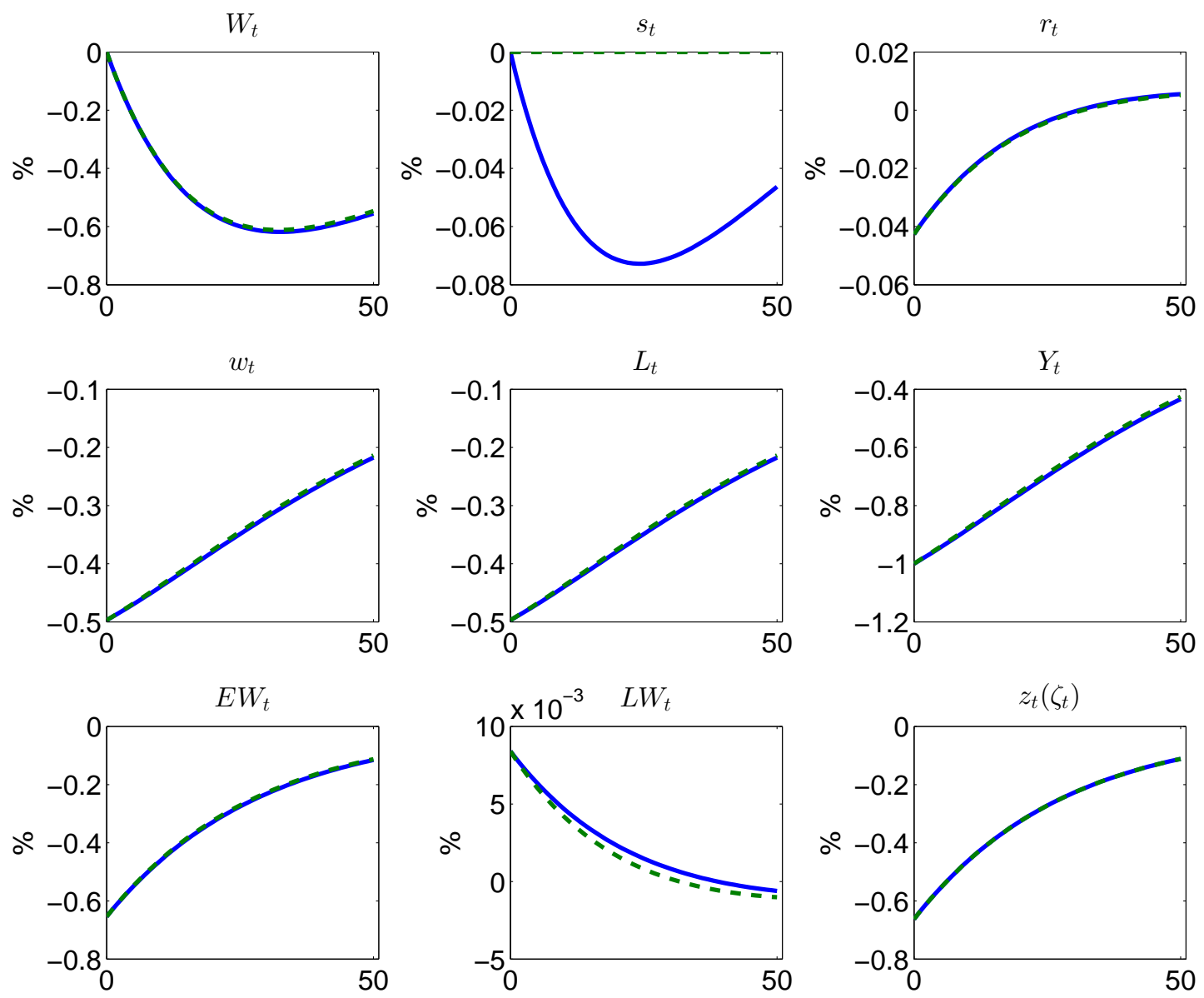

- Without transfer by government

- - - With transfer by government

Notes 1 . Percentage deviations from the steady state are shown.

2. Convergence times are 196 periods (without transfer by government) and 206 periods (with transfer by government). We judge convergence when the deviation is less than $0.01 \%$. 
Figure 6: Response to a financial shock ( $\theta$ shock $)$
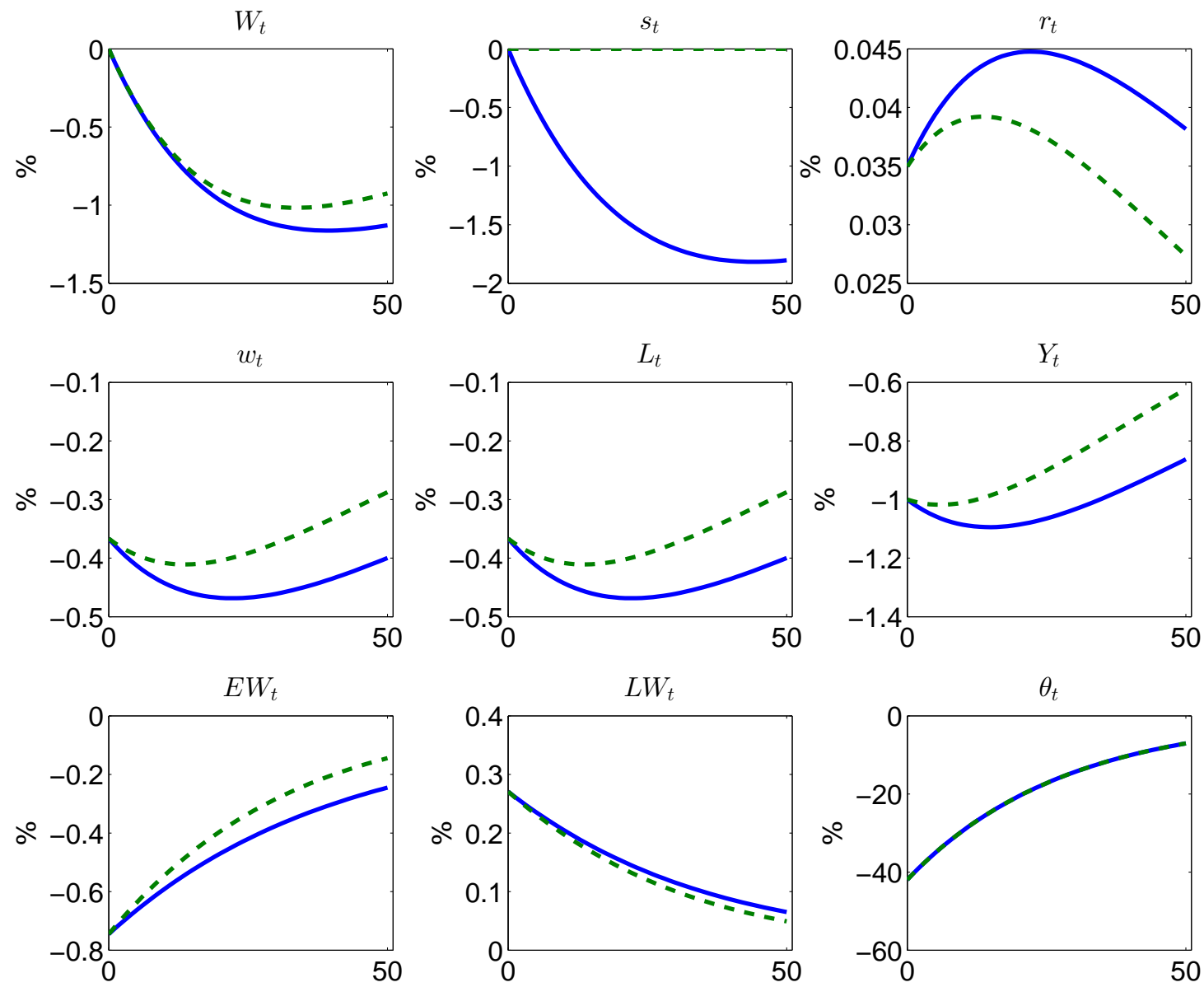

- Without transfer by government

- - - With transfer by government

Notes 1. Percentage deviations from the initial steady state are shown.

2. Convergence times are 365 periods (without transfer by government) and 228 periods (with transfer by government). We judge convergence when the deviation is less than $0.01 \%$. 
These results imply that the persistent recessions seen in the aftermath of financial crises may be explained by financial shocks (i.e., shocks on $\theta$ ) and that the redistribution of wealth is the key factor that amplifies the persistence and hump shape in output and labor. Yet, the response of LW is countercyclical in our simulation, which is contrary to that observed in previous financial crises.

In the next subsection, we therefore consider the conditions to generate procyclical LW.

\subsection{Response to an extremely large financial shock}

An extremely large financial shock, causing a large change in the parameter $\theta$, can reproduce procyclical LW. If the collateral ratio $\theta$ changes in a way that the borrowing constraint (22), which was nonbinding before, becomes binding after the shock hits, output declines and LW deteriorates to a large extent in response to the shock.

Figure 7 shows the result of the following numerical experiment. Initially, the parameter is sufficiently large, say, $\theta=1$, and the economy is at the steady state where (22) does not bind. ${ }^{16}$ At this initial steady state, there is no $\mathrm{LW}$, that is, $L W_{t}=M R S / M P L=1$, and the share of wealth owned by high firms satisfies $s=n$. Suppose a large financial shock hits the economy and $\theta$ changes permanently to 0.3 . As the borrowing constraint becomes tighter and permanently binding, output declines and LW deteriorates. The movements in output, labor, EW, and LW shown in Figure 7 are qualitatively similar to the movements of these variables during the Great Depression reported by Chari et al. (2007). Another interesting feature of this result is that the wealth share $s_{t}$ increases significantly and permanently as a result of the large financial shock: the initial steady-state value of $s_{t}$ is $n=0.1$, while it converges to the new steady-state value, 0.504 . This result seems to be consistent with the argument put forward by Piketty (2014), which states that permanent redistribution from unproductive to productive agents is associated with chronic recession in the aftermath of a financial crisis. ${ }^{17}$

\footnotetext{
${ }^{16}$ The steady state is similar to the one in Section 2.3 , in which only high firms produce output and low firms purchase the bonds issued by high firms.

${ }^{17}$ Another notable result is that the interest rate is lowered in response to the financial shock because
} 
Figure 7: Response to large financial shocks
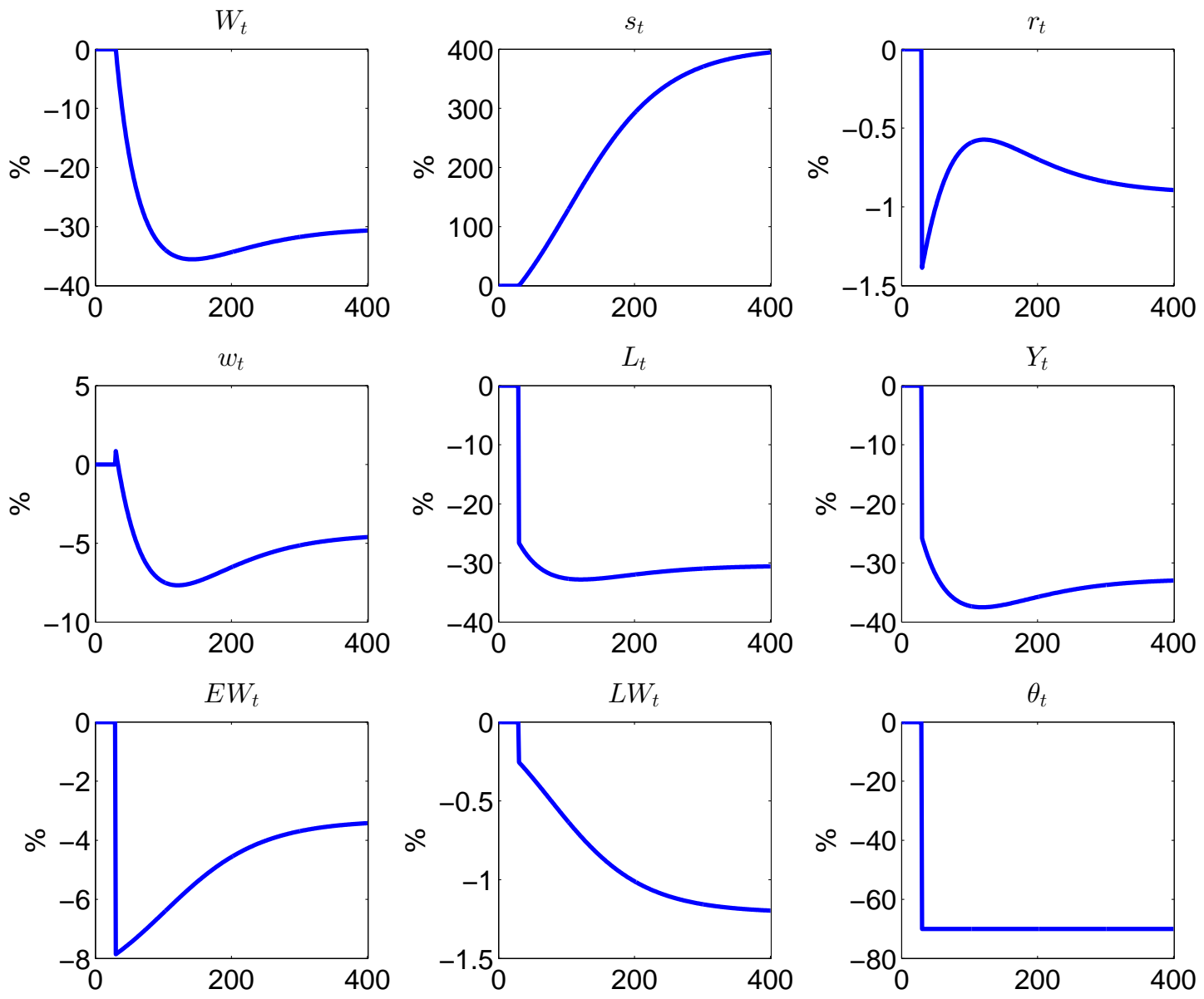

Notes 1. Percentage deviations from the initial steady state are shown.

2. Convergence time is 658 periods. We judge convergence when the deviation is less than $0.01 \%$.

\section{Conclusion}

By using a simple heterogeneous agent economy model with borrowing constraints, this study showed that the redistribution of wealth could reproduce persistence and nonlinearity in output and labor, traits that are typically observed in the aftermath of financial crises. In this model, as the borrowing constraint limits the accumulation of wealth, changes in the aggregate amount of wealth are persistent. As a result, the macroeconomic variables become persistent as well. The hump shape in the macroeconomic variables is

the borrowing constraint is tightened. A persistently low interest rate has been observed in Japan since the 1990s, that is, after the bursting of the asset-price bubble. Our result implies that a financial shock may thus explain the performance of the Japanese economy in the 1990s. 
caused by the nonlinear effect of the share of wealth on the aggregate amount of wealth. This model thus suggests that the redistribution of wealth could be one of the key driving forces behind the transmission of financial shocks in the aftermath of financial crises. The presented numerical simulation showed that productivity shocks do not generate a hump-shaped response in the economy, whereas financial shocks do, with these responses heavily amplified by the redistribution of wealth between high and low firms.

However, one limitation of our model is that it does not successfully reproduce the procyclicality of LW in response to small financial and productivity shocks; it only reproduces procyclical LW when the financial shock is extremely large. Therefore, it is still a challenge for macroeconomic research to construct a well-developed model that can explain the procyclicality of LW. Future research in this field could explore this aspect in greater detail.

\section{References}

Altig, David, Lawrence Christiano, Martin Eichenbaum, and Jesper Linde (2011) "FirmSpecific Capital, Nominal Rigidities and the Business Cycle," Review of Economic Dynamics, Vol. 14, No. 2, pp. 225-247, April.

Arellano, Cristina, Yan Bai, and Patrick J. Kehoe (2012) "Financial frictions and fluctuations in volatility," Staff Report 466, Federal Reserve Bank of Minneapolis.

Bernanke, Ben S. and Mark Gertler (1989) "Agency Costs, Net Worth, and Business Fluctuations," American Economic Review, Vol. 79, No. 1, pp. 14-31, March.

Bernanke, Ben S., Mark Gertler, and Simon Gilchrist (1999) "The Financial Accelerator in a Quantitative Business Cycle Framework," in John B. Taylor and Michael Woodford eds. Handbook of Macroeconomics, Vol. 1: Elsevier, Chap. 21, pp. 1341-1393.

Buera, Francisco and Juan Pablo Nicolini (2013) "Liquidity Traps and Monetary Policy: Managing a Credit Crunch," March. mimeo. 
Campbell, Jeffrey R. and Zvi Hercowitz (2009) "Welfare implications of the transition to high household debt," Journal of Monetary Economics, Vol. 56, No. 1, pp. 1-16, January.

(2011) "The financial labor supply accelerator," Working Paper Series WP-201105, Federal Reserve Bank of Chicago.

Carlstrom, Charles T. and Timothy S. Fuerst (1997) "Agency Costs, Net Worth, and Business Fluctuations: A Computable General Equilibrium Analysis," American Economic Review, Vol. 87, No. 5, pp. 893-910, December.

Chari, Varadarajan V., Patrick J. Kehoe, and Ellen R. McGrattan (2007) "Business Cycle Accounting," Econometrica, Vol. 75, No. 3, pp. 781-836, May.

Christiano, Lawrence J., Martin Eichenbaum, and Charles L. Evans (1999) "Monetary policy shocks: What have we learned and to what end?" in John B. Taylor and Michael Woodford eds. Handbook of Macroeconomics, Vol. 1 of Handbook of Macroeconomics: Elsevier, Chap. 2, pp. 65-148.

(2005) "Nominal Rigidities and the Dynamic Effects of a Shock to Monetary Policy," Journal of Political Economy, Vol. 113, No. 1, pp. 1-45, February.

Cordoba, Juan-Carlos and Marla Ripoll (2004) "Credit Cycles Redux," International Economic Review, Vol. 45, No. 4, pp. 1011-1046, November.

Jermann, Urban and Vincenzo Quadrini (2012) "Macroeconomic Effects of Financial Shocks," American Economic Review, Vol. 102, No. 1, pp. 238-271, February.

Kehoe, Timothy J. and Edward C. Prescott eds. (2007) Great Depressions of the Twentieth Century, Minneapolis: Federal Reserve Bank of Minneapolis.

Kiyotaki, Nobuhiro (1998) "Credit and Business Cycles," The Japanese Economic Review, Vol. 49, No. 1, pp. 18-35, March.

Kiyotaki, Nobuhiro and John Moore (1997) "Credit Cycles," Journal of Political Economy, Vol. 105, No. 2, pp. 211-248. 
(2012) "Liquidity, Business Cycles, and Monetary Policy," NBER Working Papers 17934, National Bureau of Economic Research, Inc.

Kobayashi, Keiichiro and Masaru Inaba (2006) "Business cycle accounting for the Japanese economy," Japan and the World Economy, Vol. 18, No. 4, pp. 418-440, December.

Kobayashi, Keiichiro, Tomoyuki Nakajima, and Masaru Inaba (2012) "Collateral Constraint And News-Driven Cycles," Macroeconomic Dynamics, Vol. 16, No. 5, pp. $752-$ 776, November.

Mendoza, Enrique G. (2010) "Sudden Stops, Financial Crises, and Leverage," American Economic Review, Vol. 100, No. 5, pp. 1941-1966, December.

Mulligan, Casey B. (2002) "A Dual Method of Empirically Evaluating Dynamic Competitive Equilibrium Models with Market Distortions, Applied to the Great Depression \& World War II," NBER Working Papers 8775, National Bureau of Economic Research, Inc.

Pescatori, Andrea and Murat Tasci (2011) "Search frictions and the labor wedge," Working Paper 1111, Federal Reserve Bank of Cleveland.

Piketty, Thomas (2014) Capital in the Twenty-First Century, Cambridge, MA: Harvard University Press.

Reinhart, Carmen M. and Kenneth S. Rogoff (2009) This Time Is Different: Eight Centuries of Financial Folly, Princeton: Princeton University Press.

Romer, David (2011) Advanced Macroeconomics, New York: McGraw-Hill, 4th edition.

Shimer, Robert (2009) "Convergence in Macroeconomics: The Labor Wedge," American Economic Journal: Macroeconomics, Vol. 1, No. 1, pp. 280-97, January.

Shirai, Daichi (2014) "A note on the hump-shaped output in RBC model," Technical report, The Canon Institute for Global Studies. mimeo. 
Smets, Frank and Raf Wouters (2003) "An Estimated Dynamic Stochastic General Equilibrium Model of the Euro Area," Journal of the European Economic Association, Vol. 1, No. 5, pp. 1123-1175, September.

\section{Appendix: Dynamics of the generalized model when $s_{t}$ is}

\section{large}

Here, we describe the calculation method of the generalized model introduced in Section

3 in the case where

$$
\frac{s_{t}}{1-\frac{\theta-z^{\frac{1}{\alpha}} x_{t} w_{t+1}}{r_{t}}} \geq 1 .
$$

If this inequality holds, then $\hat{K}_{t+1}=K_{t+1}$ and $K_{t+1}^{\prime}=0$. In this case, the variables are calculated by using the following procedures. The wage is determined by the following:

$$
w_{t+1}=[(1-\alpha) z]^{\frac{\nu}{\alpha+\nu}} \omega^{\frac{\alpha}{\alpha+\nu}}\left(\beta W_{t}\right)^{\frac{\alpha \nu}{\alpha+\nu}}
$$

The market interest rate is depicted as follows:

$$
R_{t}=\alpha z^{\frac{1}{\alpha}}\left(\frac{1-\alpha}{w_{t+1}}\right)^{\frac{1-\alpha}{\alpha}}+1-\delta .
$$

The evolution of the state variables is governed by the following:

$$
\begin{aligned}
& W_{t+1}=R_{t} \beta W_{t}, \\
& s_{t+1}=\gamma s_{t}+(1-\gamma) \frac{n}{1-n}\left(1-s_{t}\right) .
\end{aligned}
$$

